\title{
Effect of Testing Rate on Adhesion Properties of Acrylonitrile-Butadiene Rubber/Standard Malaysian Rubber Blend-Based Pressure-Sensitive Adhesive
}

\author{
B. T. Poh and Junidah Lamaming \\ School of Industrial Technology, Universiti Sains Malaysia, Minden, 11800 Penang, Malaysia \\ Correspondence should be addressed to B. T. Poh; btpoh@usm.my
}

Received 23 May 2013; Revised 6 September 2013; Accepted 18 September 2013

Academic Editor: Fahmina Zafar

Copyright (C) 2013 B. T. Poh and J. Lamaming. This is an open access article distributed under the Creative Commons Attribution License, which permits unrestricted use, distribution, and reproduction in any medium, provided the original work is properly cited.

\begin{abstract}
The dependence of loop tack, peel strength, and shear strength of NBR/SMR L blend-based pressure-sensitive adhesives on the rate of testing was investigated using coumarone-indene resin and toluene as the tackifier and solvent, respectively. A 40\% NBR content in the NBR/SMR L blend was used throughout the experiment. The adhesion properties were measured by a Lloyd Adhesion Tester operating at different rates of testing. The result indicates that loop tack, peels strength, and shear strength increase with the rate of testing due to the viscoelastic response of the adhesive. At low testing rate, the failure mode is cohesive in nature whereas adhesion failure mode occurs at higher testing rates. Adhesion properties also increase with the increase in adhesive coating thickness, an observation which is attributed to the wettability of the adhesive and viscoelastic behavior of the rubber blend.
\end{abstract}

\section{Introduction}

Natural rubber has been commonly used to prepare pressuresensitive adhesives. In order to increase the adhesion property of the adhesive, it is necessary to add tackifying resins such as wood resin, terpene resin, and petroleum-based resins to the rubber adhesive [1]. Besides tackifying resins, other parameters that affect the adhesion properties of rubber-based adhesives are temperature, coating thickness, molecular weight of rubber, rate of testing, and coating substrates. Recently, Rezaeian et al. [2] have reviewed the rubber adhesion to different substrates and its importance in industrial applications. Riyajan and Pheweaw [3] have studied the modification of skim rubber blended with poly(vinyl alcohol) to be applied as a biodegradable pressuresensitive adhesive. Meanwhile, Stephen et al. [4] reported the adhesive formulations with ternary blends using simplex lattice design. Thitithammawong et al. [5] found that chlorinated epoxidized natural rubber adhesives exhibited higher shear strength compared to some commercial adhesives. Several studies on the adhesion properties of natural rubber-based adhesives have also been carried out. These include the investigation of the adhesion properties of styrene-natural rubber (SNR) adhesives [6] and adhesion properties of filled rubber adhesives [7-9]. However, with respect to adhesion properties of polymer blends, very few works were reported in the literature. Phillips et al. $[10,11]$ have studied the adhesive properties of polymer blends using block copolymers as the elastomers whereas Smitthipong et al. [12] reported on the self-adhesion of immiscible polyisoprene rubber-hydrogenated acrylonitrilebutadiene rubber blends. The effects of blend ratio on the adhesion properties of rubber blend-based adhesives were also systematically investigated in our recent study [13-15]. Results show that adhesion properties strongly depend on the nature of rubber blend and its blend ratio. All these polymer blend studies are concerned with the adhesion behavior of adhesives at one fixed testing rate. Since rubber adhesive is a viscoelastic material, testing rate is an important parameter in the adhesion behavior of the polymer blendbased adhesive. In view of this scarcity of the data, it is thus the aim of this paper to report our findings on the effect of testing rate on the tack, peel, and shear strength of acrylonitrile-butadiene rubber (NBR)/Standard Malaysian Rubber (SMR L) blend-based adhesive at various coating thicknesses. 


\section{Experiment}

2.1. Materials. SMR L grade natural rubber and acrylonitrilebutadiene rubber (NBR) were used as the elastomers. SMR $\mathrm{L}$ and NBR were supplied by Rubber Research Institute of Malaysia and Bayer Company, respectively. The bound acrylonitrile content in NBR is 33\%. The glass transition temperatures for SMR L and $\mathrm{NBR}$ are $-72^{\circ} \mathrm{C}$ and $-40^{\circ} \mathrm{C}$, respectively. Coumarone-indene resin was used as the tackifier and was freshly supplied by Mukmin Enviro Company, Penang (Malaysia). Commercial grade toluene was used as the solvent throughout the study. All materials and chemicals were used as supplied without any purification.

2.2. Adhesive Preparation. The rubber was masticated using a 2-roll mill for 10 minutes. NBR/SMR L blends ratios were fixed at $2 / 3$ corresponding to $40 \%$ NBR in the blend. Then $5 \mathrm{~g}$ of the rubber blend was dissolved in $30 \mathrm{~mL}$ of toluene and the solution was tightly closed and left for 24 hours to ensure complete dissolution. A fixed amount of $2 \mathrm{~g}$ of pulverized coumarone indene resin, corresponding to $40 \mathrm{phr}$ of resin, was then added slowly to the rubber solution with constant stirring. The adhesive was left for 3 hours at room temperature $\left(30^{\circ} \mathrm{C}\right)$ prior to testing.

\section{Testing}

3.1. Tack. A PET substrate with dimension of $4 \mathrm{~cm} \times 25 \mathrm{~cm}$ was coated at the centre of the film $(4 \mathrm{~cm} \times 4 \mathrm{~cm})$ with various coating thicknesses using a SHEEN hand coater. The coated sample was then conditioned at room temperature for 24 hours before testing. A loop was formed and the adhesivecoated area was slowly brought into contact with a glass without any force other than the pushing force on the loop. Testing was carried out using a Llyod Adhesion Tester (Model LRXPlus with NEXYGEN software) operating at different testing rates, that is, $10,20,30,40,50$, and $60 \mathrm{~cm} / \mathrm{min}$, to debond the loop from the glass plate. The average debonding force was noted from the three highest peaks recorded.

3.2. Peel Strength. PET film was used for the base stock and face stock in the peel tests, that is, T peel, $90^{\circ}$ peel, and $180^{\circ}$ peel tests. The dimensions of PET film for the $\mathrm{T}$ peel test were $20 \mathrm{~cm} \times 4 \mathrm{~cm}$. For the $90^{\circ}$ peel test, the dimensions were $20 \mathrm{~cm} \times 4 \mathrm{~cm}$ and $15 \mathrm{~cm} \times 7 \mathrm{~cm}$ for the base stock and face stock, respectively. The respective dimensions of the substrate were $25 \mathrm{~cm} \times 4 \mathrm{~cm}$ and $10 \mathrm{~cm} \times 10 \mathrm{~cm}$ for the $180^{\circ}$ peel test. The adhesive was coated from the end of the PET film at a coating area of $10 \mathrm{~cm} \times 4 \mathrm{~cm}$ using a SHEEN hand coater. The face stock was gently laid on the base stock. The coated sample was then conditioned at room temperature for 24 hours before testing. A Llyod Adhesion Tester operating at different testing rates was used to determine the peel force of the coated samples. The average peeling force was computed from the three highest peaks recorded. Peel strength is expressed as the average load per width of the bond line required to separate progressively a flexible member from a rigid member or another flexible member (ASTM D 907).

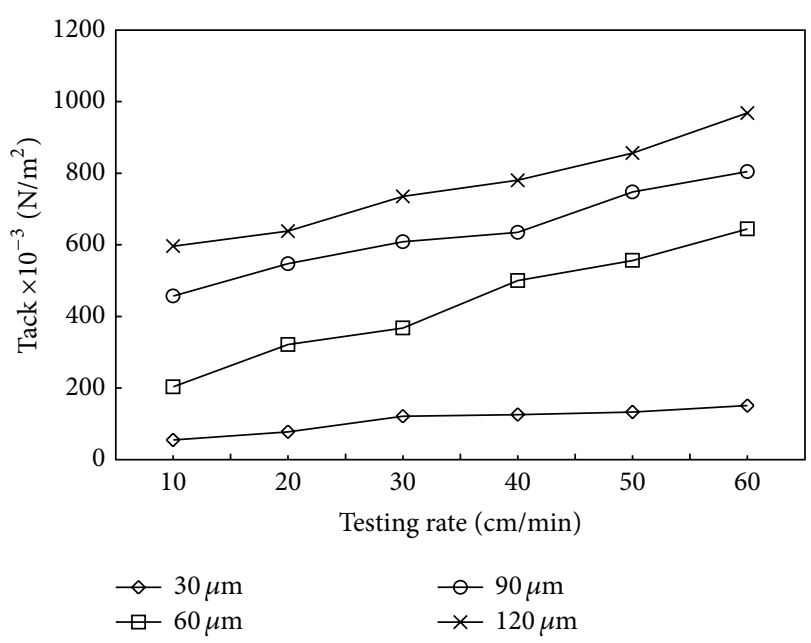

FIGURE 1: Variation of tack with testing rate for NBR/SMR L blendbased adhesive at various coating thicknesses.

3.3. Shear Strength. The shear strength was carried out according to the modified ASTM D 3165-95. A $20 \mathrm{~cm} \times$ $4 \mathrm{~cm}$ dimension of the PET film was used for the shear test. Adhesive was coated on the substrate with a coating area of $10 \mathrm{~cm} \times 4 \mathrm{~cm}$ from the end of the base stock. The face stock $(20 \mathrm{~cm} \times 4 \mathrm{~cm})$ was then placed on the coated area of the base stock. The coated sample was conditioned at room temperature $\left(30^{\circ} \mathrm{C}\right)$ for 24 hours before testing on a Lloyd Adhesion Tester operating at various testing rates. Testing was conducted at a distance of $10 \mathrm{~cm}$ which corresponded to the coated length of the sample. The peak force recorded was taken as the shear force. Shear strength was defined as the shear force per unit area of testing $\left(\mathrm{N} / \mathrm{m}^{2}\right)$.

\section{Results and Discussion}

The dependence of adhesion properties of NBR/SMR L blends pressure sensitive adhesives on rate of testing is discussed below.

4.1. Tack. The effect of rate of testing on the loop tack of adhesives prepared at various coating thicknesses is shown in Figure 1. The tack increases with increasing the rate of testing, an observation which is associated with the change in failure modes. At low rates of testing, the response is predominantly viscous and cohesive failure occurs, whilst at the high rate of testing, the response is predominantly elastic resulting in the adhesion failure [1]. Cohesive failure of the adhesives happens when adhesive remains on the substrate where the attachment of the adhesive to the substrate is stronger than the internal strength of the adhesive itself; that is, the adhesive fails within its bulk. When the elastic component of rubber becomes significant as the rate of testing increases, the failure mode is essentially adhesive in nature where detachment of adhesive from substrate takes place and clean substrate surface is observed. However, at the lowest coating thickness, that is, $30 \mu \mathrm{m}$, the rate of increase in tack with testing 


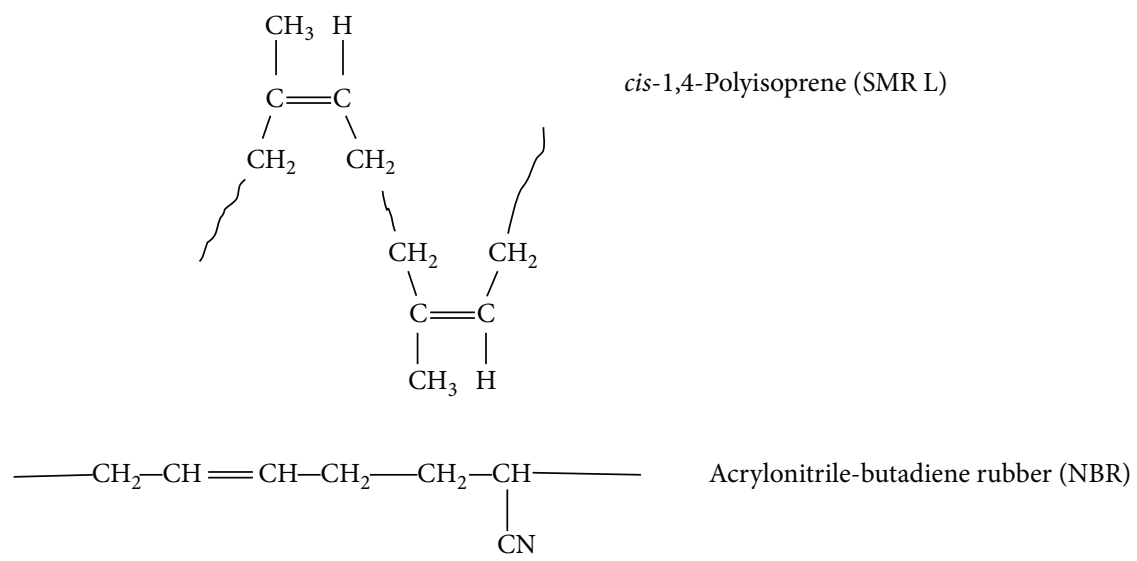

FiguRe 2

rate is much lower than that at the other higher coating thicknesses especially after $30 \mathrm{~cm} / \mathrm{min}$ of testing rate. This observation is attributed to the smaller amount of adhesive material present at lower coating thickness which provides lesser elastic effect on the tack property. The microstructure of natural rubber (SMR L) is a cis-1,4-polyisoprene whereas NBR is a linear copolymer of acrylonitrile and butadiene as shown in Figure 2.

Therefore after blending, the rubber blend-based adhesive consists of a mixture of linear NBR and cis-1,4-polyisoprene (SMR L). At low rate of testing, the cis-structure of SMR L has time to uncoil itself to become a linear structure comparable to that of NBR, hence viscous flow is facilitated. However, at high rate of testing, the cis-structure of SMR L cannot respond to the applied stress immediately and hence the elastic component of the adhesive is increased as shown by the higher tack value in Figure 1.

In all cases, for a fixed testing rate, tack value increases with coating thickness increase. This finding is ascribed to the larger amount of adhesive at higher coating thickness which enhances the viscoelastic response of the adhesive as shown in our results reported earlier [13-15] on natural rubber blendbased pressure sensitive adhesives.

4.2. Peel Strength. Figures 3, 4, and 5 show the effect of rate of testing on the peel strength for $\mathrm{T}, 90^{\circ}$, and $180^{\circ}$ peel tests, respectively. All the graphs indicate that the peel strength increases with an increase in peeling rate. This observation is ascribed to the cohesive failure which occurs at low peeling rate where the viscoelastic response is predominantly viscous as discussed earlier in the tack property. This type of failure is due to the inability of an adhesive to resist internal separation. However, as the peeling rate is increased, the viscoelastic response shifts to the predominantly elastic response which enhances the adhesive strength as reflected by the higher peel strength $[16,17]$. Owing to cis-microstructure of SMR $\mathrm{L}$, the rubber is able to relax at low rate of testing. At high rate of testing, the cis-structure of SMR L is not able to respond to the applied stress; hence higher peel strength is observed due to the increase in the elastic component of the adhesive. Adhesion failure happened at the interface between

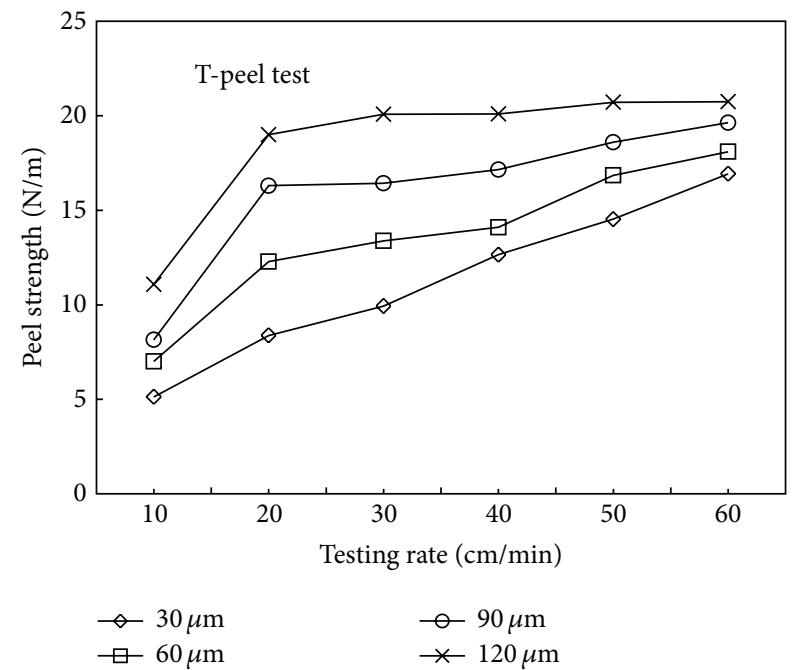

FIGURE 3: Variation of peel strength (T peel) with testing rate for NBR/SMR L blend-based adhesive at various coating thicknesses.

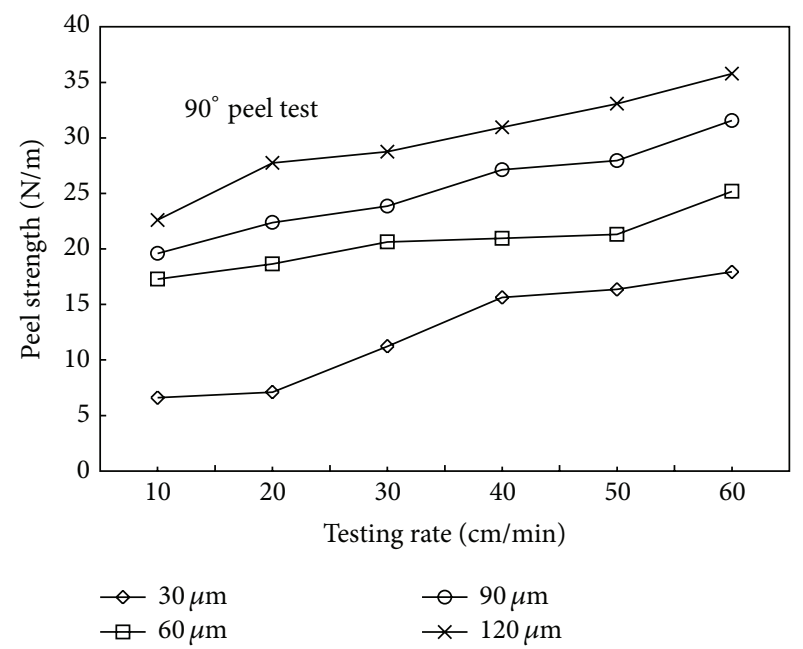

FIGURE 4: Variation of peel strength $\left(90^{\circ}\right.$ peel test) with testing rate for NBR/SMR L blend-based adhesive at various coating thicknesses. 


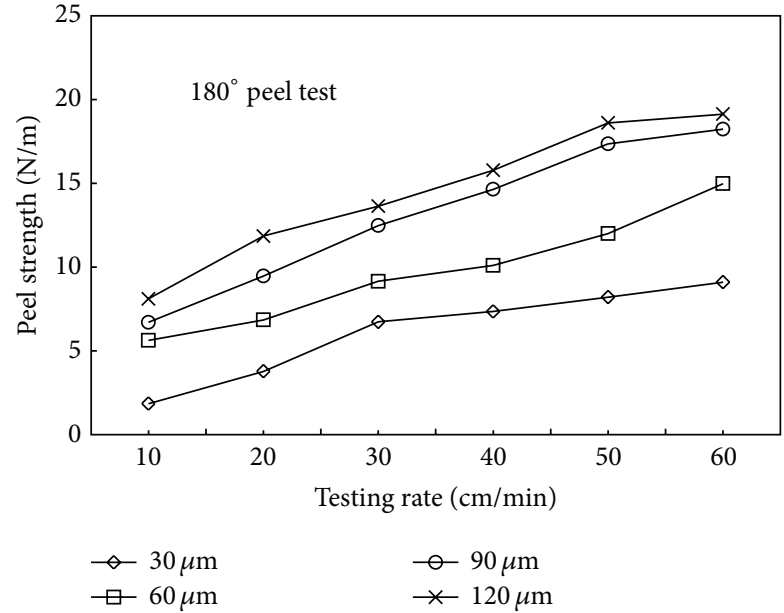

FIGURE 5: Variation of peel strength $\left(180^{\circ}\right.$ peel test) with testing rate for NBR/SMR L blend-based adhesive at various coating thicknesses.

the adhesive and the substrate. It is generally agreed that the transition from cohesive to adhesive failure is associated with the transition from liquid-like viscous to rubber-like elastic behaviour [1].

Figure 6 indicates that for the three modes of peel tests, peel strength obtained from the $90^{\circ}$ peel test consistently shows the highest peel value followed by the $\mathrm{T}$ and $180^{\circ}$ peel tests. This observation is attributed to the angle of testing where higher strain-induced crystallization [18] in $90^{\circ}$ peel test renders the adhesives to become a tough solid that cannot be easily ruptured. The microstructure of SMR L is in the cis-form as shown above in the Tack section. This means that SMR L molecular chain is in random coiled conformation. When a tensile force is applied perpendicular to the plane direction $\left(90^{\circ}\right.$ peel test), the random coil of rubber chain uncoils itself and becomes a straight molecular chain. The straight rubber chains then align themselves to become a three-dimensional order structure; the rubber is said to undergo strain-induced crystallization to become a tough solid. Crystallizable rubber possesses high mechanical strength. Therefore, the $90^{\circ}$ peel test requires higher peeling force to separate the mechanical interlocking and anchorage of the adhesion in pores and irregularities in the substrate; that is, the adhesive layer itself cannot be easily ruptured and higher peel strength is observed $[19,20]$. Figure 7 shows the effect of coating thickness on peel strength at $90^{\circ}$-peel test at three selected testing rates. For a fixed testing rate, peel strength increases with coating thickness. The $120 \mu \mathrm{m}$ coated sample shows the highest peel strength; an observation which is attributed to the increasing amount of adhesive present in the sample. This means that more adhesive is available to enhance the wettability on the substrate, thus giving high value on peeling strength.

4.3. Shear Strength. Figure 8 exhibits the dependence of rate of testing on the shear strength at various coating thicknesses. As in the other adhesion properties, shear strength

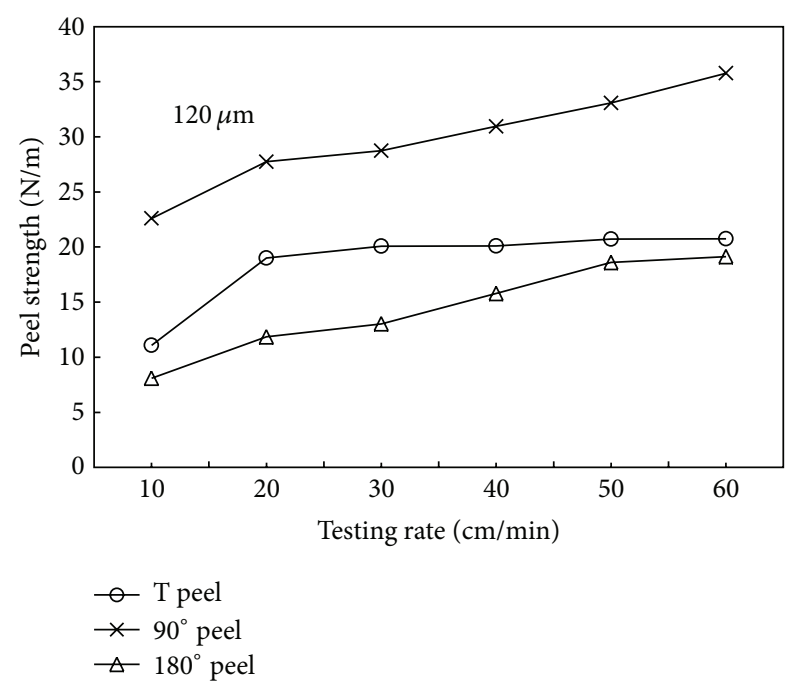

FIGURE 6: Comparison of peel strength for various modes of peel tests at $120 \mu \mathrm{m}$ coating thickness.

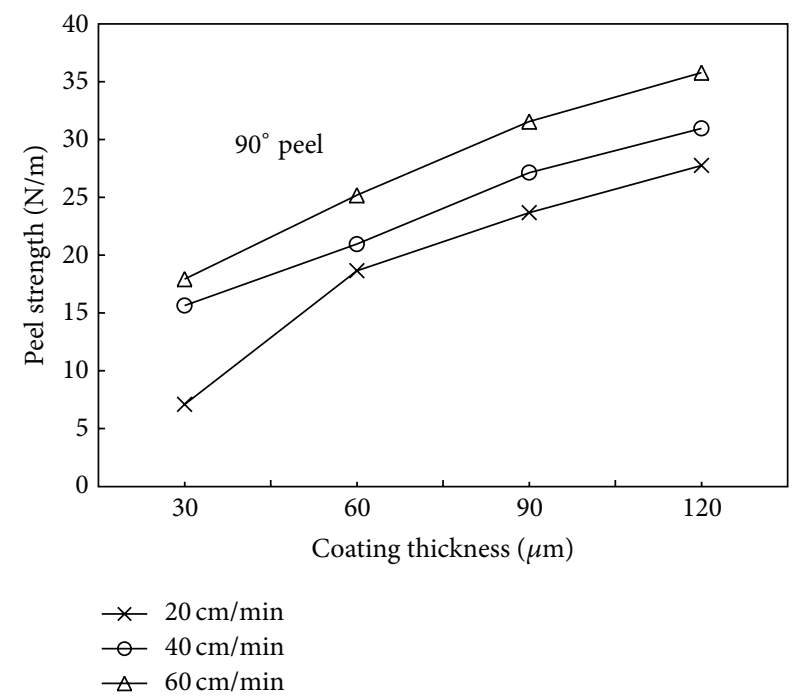

FIgURE 7: Variation of peel strength $\left(90^{\circ}\right.$ peel test) with coating thickness for various testing rates.

also increases with the rate of testing. This observation is attributed to the increasing effect of elastic component of the adhesive as the rate of testing is increased as discussed earlier in the Tack section. The predominant adhesive failure at higher testing rate accounts for higher shear resistance compared to the cohesive failure mode at lower testing rate. Adhesive hardens at high strain levels to become a tough solid and the adhesive layer cannot be easily ruptured [21]. The dependence of shear strength on coating thickness for various testing rates is shown in Figure 9. From the graph, shear strength of adhesive increases with coating thickness just like the other adhesion results reported in this study. Again, the $120 \mu \mathrm{m}$ coated sample consistently illustrates the highest shear strength compared with the other coating thickness, an observation which is associated with the presence of 


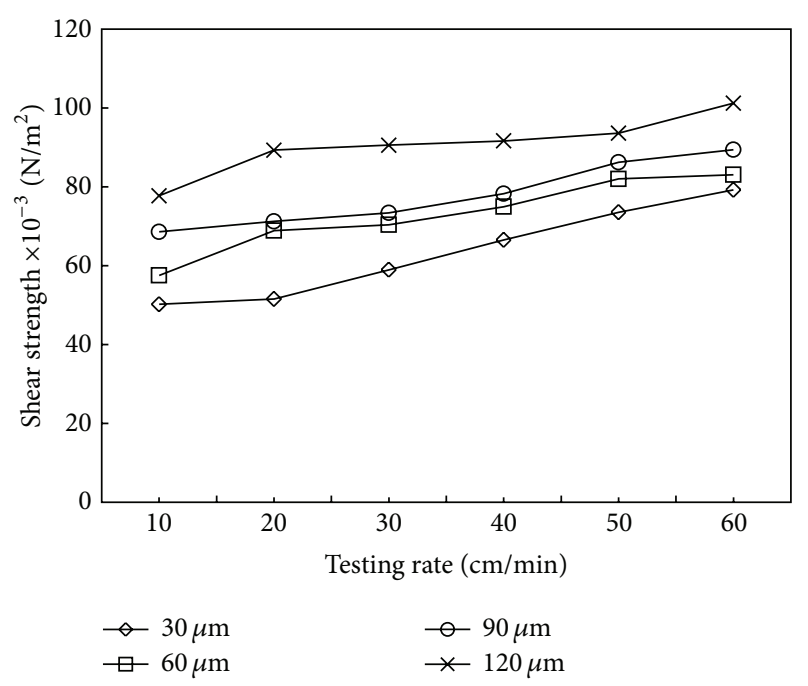

FIGURE 8: Variation of shear strength with testing rate for NBR/SMR $\mathrm{L}$ blend-based adhesive at various coating thicknesses.

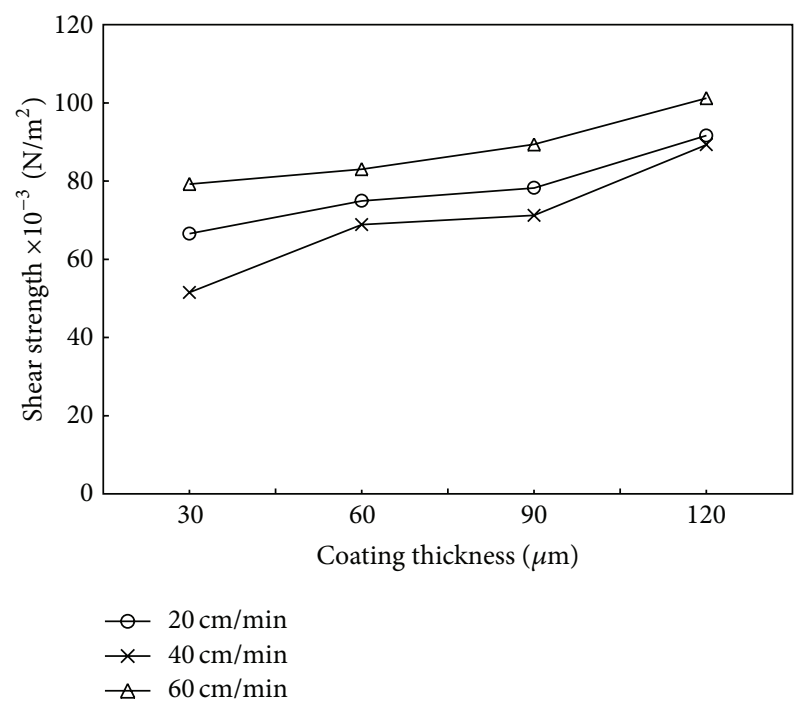

FIGURE 9: Variation of shear strength with coating thickness for various testing rates.

higher amount of adhesive at higher coating thickness. The viscoelastic behavior of higher amount of rubber component enhances the shear resistance of the adhesive as coating thickness is increased; thus higher shear strength is observed for thicker coated substrate.

\section{Conclusion}

Loop tack of NBR-/SMR L-based adhesive increases with the increase in the rate of testing, an observation which is attributed to the change in failure modes. At low rate of testing, the response is predominantly viscous, thus promoting cohesive failure to occur. However, at higher testing rate, the viscoelastic response is predominantly elastic and adhesive failure mode becomes significant. From all the three modes of peel test, peel strength increases with an increase in peeling rate due to the transition from cohesive failure to adhesive failure modes as testing rate is increased. Peel strength of the $90^{\circ}$-peel test consistently shows the highest peel value followed by the $\mathrm{T}$ and $180^{\circ}$ peel test. This observation is ascribed to the angle of testing, where higher strain-induced crystallization occurs in the former peel test mode. Shear strength also indicates an increase in value with increasing rate of testing. In all the adhesion tests, $120 \mu \mathrm{m}$ coating thickness exhibits higher adhesion values compared with the lower coated samples. This phenomenon is associated with the presence of higher amount of the adhesive which enhances the viscoelastic response and wettability of the adhesive. Potential applications of the NBR/SMR L blend adhesive are in the production of tapes and labels. Since NBR is well known for its oil resistant property, specialty oil resistant packaging tapes can also be prepared from the adhesive.

\section{Acknowledgment}

The authors acknowledge the science fund provided by the Ministry of Science, Technology and Innovation (MOSTI) for this study.

\section{References}

[1] D. Satas, Ed., Handbook of Pressure-Sensitive Adhesive Technology, Van Nostrand Reinhold, New York, NY, USA, 1982.

[2] I. Rezaeian, P. Zahedi, and A. Rezaeian, "Rubber adhesion to different substrates and its importance in industrial applications: a review," Journal of Adhesion Science and Technology, vol. 26, pp. 721-744, 2012.

[3] S. Riyajan and N. Pheweaw, "Modification of skim rubber blended with poly (vinyl alcohol) to be applied as a biodegradable pressure-sensitive adhesive: effect of 2,6-DI-T-butyl-4methylphenol and hydrocarbon resin," Rubber Chemistry and Technology, vol. 85, pp. 547-558, 2012.

[4] O. Stephen, R. Fatima, and A. A. Ikechukwu, "Adhesive formulations with ternary blends using simplex lattice design," International Journal of Physical Sciences, vol. 5, no. 13, pp. 20982103, 2010.

[5] A. Thitithammawong, N. Ruttanasupa, and C. Nakason, "Preparation and properties of chlorinated epoxidised natural rubber latex and its latex-based adhesive," Journal of Rubber Research, vol. 15, no. 1, pp. 19-34, 2012.

[6] S. B. Neoh, X. M. Lee, A. R. Azura, and A. S. Hashim, "Effect of in situ polymerization of styrene onto natural rubber on adhesion properties of styrene-natural rubber (SNR) adhesives," Journal of Adhesion, vol. 86, no. 8, pp. 857-871, 2010.

[7] B. T. Poh and C. F. Gan, "Viscosity and peel strength of magnesium oxide-filled adhesive prepared from epoxidized natural rubber (ENR 25)," Polymer-Plastics Technology and Engineering, vol. 49, pp. 191-194, 2010.

[8] I. Khan and B. T. Poh, "The effect of silica on the peel adhesion of epoxidized natural rubber-based adhesive containing coumarone-indene resin," Polymer-Plastics Technology and Engineering, vol. 49, pp. 1356-1360, 2010.

[9] I. Khan, B. T. Poh, and C. M. Badriah, "Effect of sodium sulfate on the viscosity, tack, and adhesion properties of SMR 10-based 
pressure-sensitive adhesive," Journal of Elastomers and Plastics, vol. 43, no. 1, pp. 85-95, 2011.

[10] J. P. Phillips, X. Deng, R. R. Stephen et al., "Nano- and bulk-tack adhesive properties of stimuli-responsive, fullerenepolymer blends, containing polystyrene-block-polybutadieneblock-polystyrene and polystyrene-block-polyisoprene-blockpolystyrene rubber-based adhesives," Polymer, vol. 48, no. 23, pp. 6773-6781, 2007.

[11] J. P. Phillips, X. Deng, M. L. Todd et al., "Singlet oxygen generation and adhesive loss in stimuli-responsive, fullerenepolymer blends, containing polystyrene-block-polybutadieneblock- polystyrene and polystyrene-block-polyisoprene-blockpolystyrene rubber-based adhesives," Journal of Applied Polymer Science, vol. 109, no. 5, pp. 2895-2904, 2008.

[12] W. Smitthipong, M. Nardin, J. Schultz, and K. Suchiva, "Adhesion and self-adhesion of immiscible rubber blends," International Journal of Adhesion and Adhesives, vol. 29, no. 3, pp. 253258, 2009.

[13] B. T. Poh and L. N. Ong, "Adhesion properties of styrenebutadiene rubber (SBR)/ Standard Malaysian Rubber (SMR L)based adhesives in the presence of phenol formaldehyde resin," eXPRESS Polymer Letters, vol. 1, pp. 654-659, 2007.

[14] B. T. Poh and S. S. Heng, "Effect of blend ratio on adhesion properties of pressure-sensitive adhesives prepared from SBR/SMR L blends," Polymer-Plastics Technology and Engineering, vol. 47, pp. 325-329, 2008.

[15] B. T. Poh and A. L. Lim, "Adhesion properties of pressuresensitive adhesives prepared from SMR 10/ENR 25, SMR 10/ENR 50, and ENR 25/ENR 50 blends," Journal of Applied Polymer Science, vol. 109, pp. 115-119, 2008.

[16] B. T. Poh and I. Khan, "Effect of test rate on adhesion properties of SMR L, ENR-25 and ENR-50-based pressure-sensitive adhesives effect of test rate on adhesion properties of SMR L, ENR25 and ENR-50-based pressure-sensitive adhesives," Journal of Adhesion Science and Technology, vol. 26, no. 6, pp. 873-881, 2012.

[17] I. Khan and B. T. Poh, "Natural rubber-based pressure-sensitive adhesives: a review," Journal of Polymers and the Environment, vol. 19, no. 3, pp. 793-811, 2011.

[18] C. K. L. Davies, S. V. Wolfe, I. R. Gelling, and A. G. Thomas, "Strain crystallization in random copolymers produced by epoxidation of cis 1,4-polyisoprene," Polymer, vol. 24, no. 1, pp. 107-113, 1983.

[19] G. Gierenz and W. Karmann, Eds., Adhesive and Adhesive Tapes, Wiley-VCH, New York, NY, USA, 2001.

[20] L. H. Lee, Adhesive Bonding, Plenum Press, New York, NY, USA, 1991.

[21] I. Skeist, Ed., Handbook of Adhesives, Van Nostrand Reinhold, New York, NY, USA, 3rd edition, 1990. 

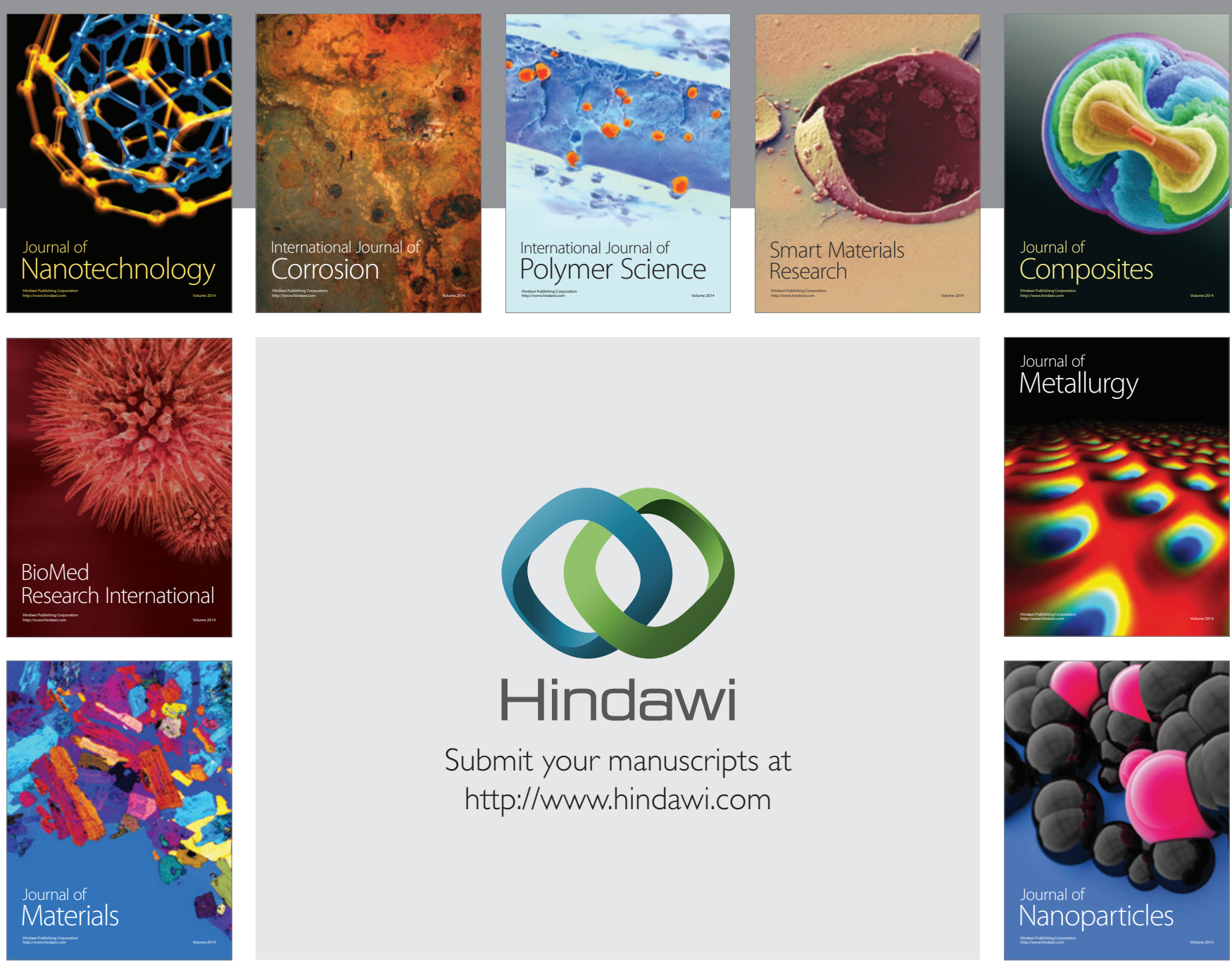

Submit your manuscripts at http://www.hindawi.com
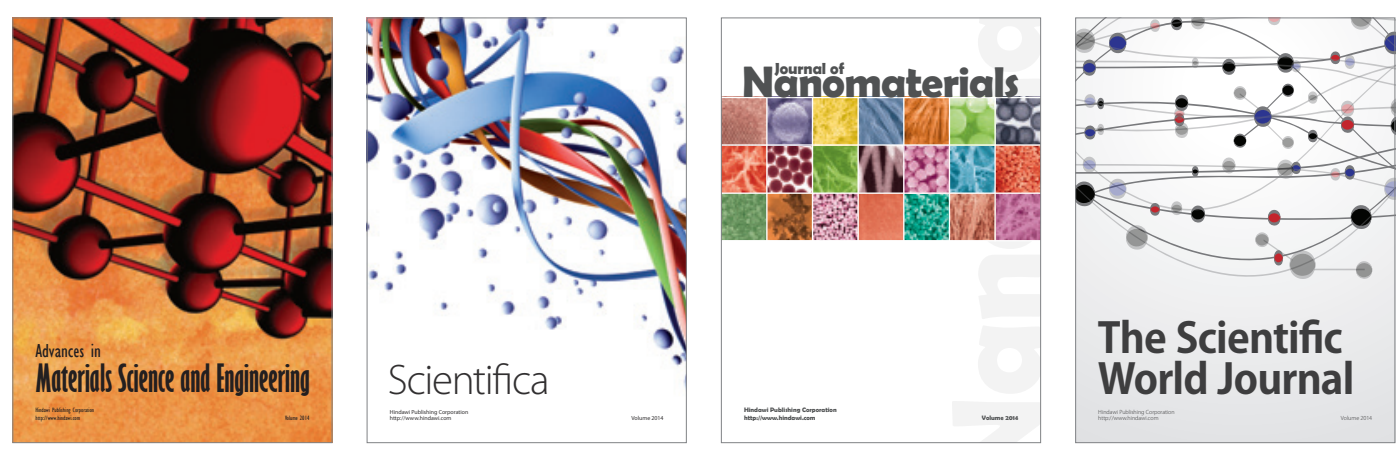

\section{The Scientific World Journal}
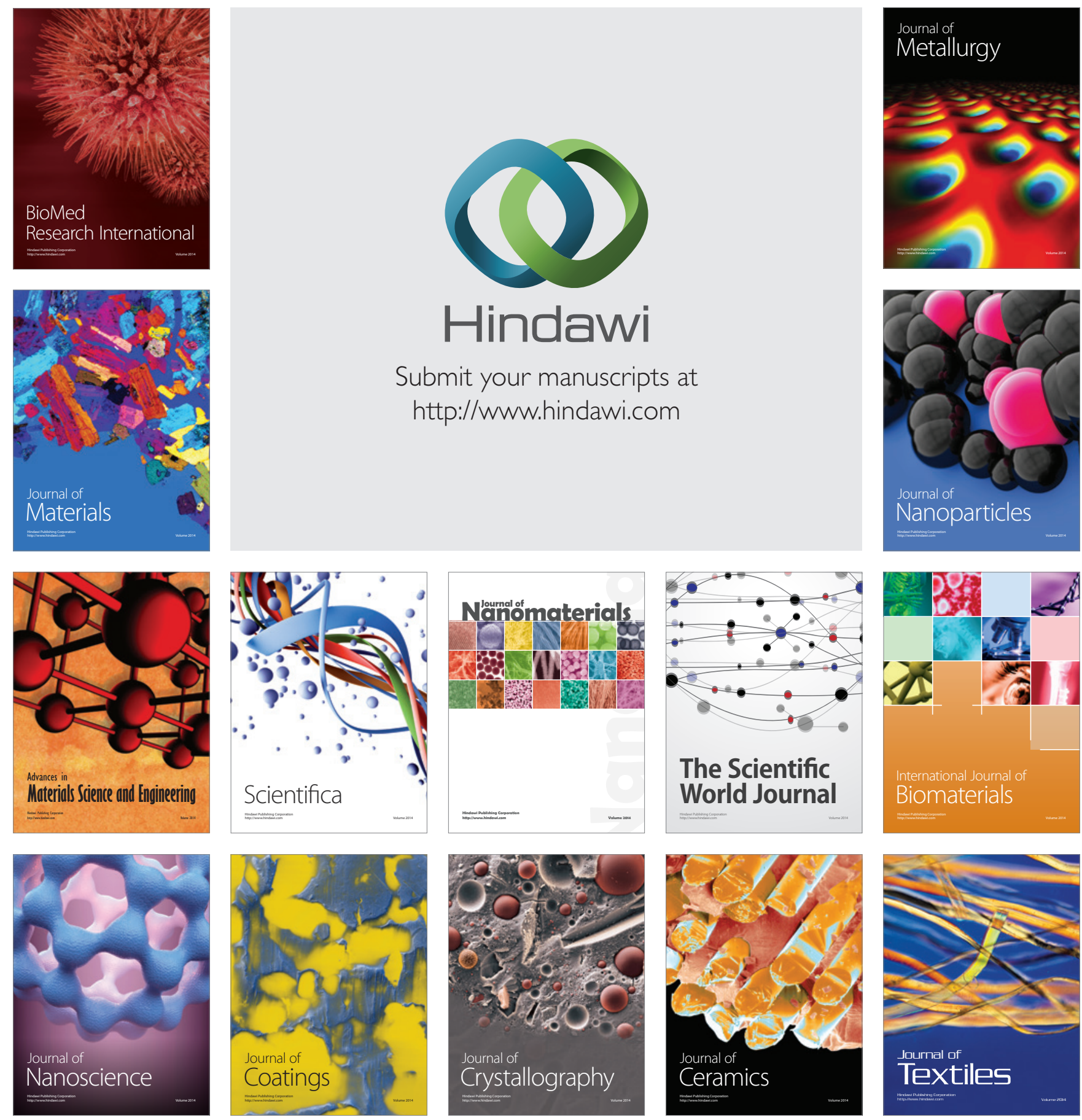